\title{
Alphavirus and flavivirus infectivity is disrupted by components of the bacterial cell wall
}

Lana Langendries ${ }^{1}$, Sofie Jacobs ${ }^{1}$, Rana Abdelnabi ${ }^{1}$, Sam Verwimp ${ }^{1}$, Suzanne Kaptein ${ }^{1}$, Pieter Baatsen², Lieve Van Mellaert ${ }^{3}$, Leen Delang ${ }^{1 \# . ~}$

1. KU Leuven, Department of Microbiology, Immunology and Transplantation, Rega Institute for Medical Research, Laboratory of Virology and Chemotherapy, 3000 Leuven, Belgium.

2. VIB-KU Leuven, Electron Microscopy Platform of VIB Bio Imaging Core, 3000 Leuven, Belgium

3. KU Leuven, Department of Microbiology, Immunology and Transplantation, Rega Institute for Medical Research, Laboratory of Molecular Bacteriology, 3000 Leuven, Belgium.

\#Corresponding author:

Prof. Leen Delang. Tel +3216322107, e-mail: leen.delang@kuleuven.be 


\section{Abstract}

The impact of the host microbiome on arbovirus infections is currently not clearly understood. Arboviruses are viruses transmitted through the bites of infected arthropods, predominantly mosquitoes or ticks. The first site of arbovirus inoculation is the biting site in the host skin, which is colonized by a complex microbial community that could possibly influence arbovirus infection. We demonstrated that pre-incubation of arboviruses with certain components of the bacterial cell wall, including lipopolysaccharides (LPS) of some Gram-negative bacteria and lipoteichoic acids or peptidoglycan of certain Gram-positive bacteria, significantly reduced arbovirus infectivity in vitro. This inhibitory effect was observed for arboviruses of different virus families, including chikungunya virus of the Alphavirus genus and Zika virus of the Flavivirus genus, showing that this is a broad phenomenon. A modest inhibitory effect was observed following incubation with a panel of heat-inactivated bacteria, including bacteria residing on the skin. No viral inhibition was observed after pre-incubation of cells with LPS. Furthermore, a virucidal effect of LPS on viral particles was noticed by electron microscopy. Therefore, the main inhibitory mechanism seems to be due to a direct effect on the virus particles. Together, these results suggest that bacteria are able to decrease the infectivity of alphaviruses and flaviviruses. 


\section{Introduction}

Arboviruses (i.e. arthropod-borne viruses) are viruses transmitted through the bites of infected arthropods, predominantly mosquitoes or ticks. It is a genetically highly diverse group with more than 600 members described, of which 80 are known to cause disease in humans and animals (1). Due to increased travelling, climate change and adaptation of the arthropod vectors to urbanization, the geographic distribution of arboviral infections has expanded and is still spreading in many regions of the world (2). Well-known medically important arboviruses are chikungunya virus (CHIKV), belonging to the Alphavirus genus of the Togaviridae, and dengue virus (DENV), Zika virus (ZIKV) and yellow fever virus (YFV), belonging to the Flavivirus genus of the Flaviviridae (3). They all typically manifest first with fever and flu-like symptoms, possibly accompanied by rash or myalgia and arthralgia (4).

Although arboviruses are very diverse, they share a common characteristic: transmission via the bite of an arthropod vector into the skin. The skin is the largest organ of the human body and has a protective role against foreign organisms or toxic substances (5). The skin epidermis and dermis are colonized by a large number of microorganisms, most of which are beneficial or harmless (6). It is estimated that between $10^{6}$ and $10^{9}$ microorganisms $/ \mathrm{cm}^{2}$ are present on the human skin (7). Microbial colonization is person-specific and depends on age, sex and environmental factors (such as clothing, use of antibiotics, soaps and cosmetics) $(5,8)$.

Microbiota are crucial for human health since they have an important role in the regulation of the mucosal immune system (9). Furthermore, the presence of microbiota induces competition with other pathogens, such as pathogenic bacteria or viruses (10). Several bacterium-virus interactions have been characterized: Lactobacillus rhamnosus and Bifidobacterium bifidum bacteria have been shown to prevent rotavirus-induced diarrhea in mice by inducing inflammatory or mucosal protective factors, respectively $(11,12)$. Several species of the Lactobacillus genus inhibited replication of HIV-1 in cervico-vaginal tissue culture by producing lactic acid causing an antiviral effect (13). For influenza virus, it has been shown that lipopolysaccharides (LPS), molecules on the outer membrane of Gram-negative bacteria, activated Toll-like receptors and inhibited viral infection by direct interaction with influenza virions $(14,15)$. For coronaviruses (CoV) (common cold associated-CoV and MERSCoV), it was recently described that peptidoglycan (PG) of Bacillus subtilis reduced coronavirus infectivity, triggered by a PG-associated cyclic lipopeptide (surfactin), which also decreased 
the infectivity of other enveloped viruses (e.g. ZIKV, CHIKV, Mayaro virus (MAYV), Ebola virus) (16). In contrast to the protective, antiviral effect of these microbiota, other bacteria were shown to promote viral infections. It has been described that gut bacteria enhanced viral replication, transmission and pathogenesis of enteric viruses, such as norovirus, poliovirus and reovirus. Human norovirus interacted with bacterial strains isolated from human stool, probably by binding HBGA (histo-blood group antigen) -like glycans and sialylated LPS present on bacterial cells, thereby enhancing viral entry $(9,17)$. Poliovirus has been shown to bind bacterial LPS, which increased virion stability and cell attachment and potentially promoted poliovirus transmission (18). Also reovirus virions directly interacted with bacteria or bacterial envelope components (LPS and PG) (19). In addition, reduced reovirus replication and pathogenesis was observed in antibiotic-treated mice (20).

Currently, little information is available on the impact of host microbiota on arbovirus infections. Oral administration of antibiotics was shown to severely aggravate flavivirus infections in mice (21). The antibiotic treatment altered the bacterial abundance in the gut and the development of optimal T cell immunity, causing detrimental effects on flavivirusinduced disease in mice (21). A comparable effect of oral antibiotic treatment on alphavirus infectivity was recently reported: perturbation of the intestinal microbiome by the antibiotics resulted in enhanced CHIKV infection by diminishing type I interferon responses in monocytes and dendritic cells (22). These data suggest that host bacteria function as protective, antiarboviral microorganisms. However, it is not clear yet whether host (skin) bacteria directly interact with arboviruses or whether indirect mechanisms are responsible for the antiviral effect. Therefore, we studied the effect of different bacterial cell wall components and inactivated skin bacteria on alphavirus and flavivirus infectivity in vitro and characterized the mechanisms of interaction. 


\section{Material and methods}

\section{Cells and viruses}

African green monkey kidney cells (Vero cells, ATCC CCL-81) and Vero E6 cells (ATCC CRL-1586) were maintained in minimal essential medium (MEM, Gibco) supplemented with $10 \%$ fetal bovine serum (FBS, Gibco), 1\% L-glutamine (Gibco), 1\% sodium bicarbonate (Gibco) and 1\% non-essential amino acids (NEAA, Gibco). Human skin fibroblasts (ATCC CRL-2522) were maintained in MEM supplemented with 10\% FBS, 1\% L-glutamine, 1\% sodium bicarbonate, $1 \%$ sodium pyruvate (Gibco) and $1 \%$ NEAA. Cell cultures were maintained at $37^{\circ} \mathrm{C}$ in an atmosphere of $5 \% \mathrm{CO}_{2}$ and $95 \%-99 \%$ relative humidity. Virus propagation and in vitro assays were performed using similar media but supplemented with 2\% FBS (assay media).

CHIKV (Indian Ocean strain 899; GenBank FJ959103.1) is a laboratory-adapted strain (a kind gift of Prof. C. Drosten, University of Bonn, Germany). Sindbis virus (SINV, strain HRsp, GenBank J02363.1) and Semliki Forest virus (SFV, Vietnam strain, GenBank EU350586.1) belong to the collection of viruses at the Rega Institute of Medical Research, Belgium. MAYV (strain TC625) and ZIKV (SL1602, Suriname; GenBank KY348640.1) were obtained via the EVAg consortium (https://www.european-virus-archive.com). YFV (17D vaccine strain; Stamaril; GenBank NC_002031.1) was obtained from Sanofi Pasteur MSD, Belgium. Virus stocks were stored at $-80^{\circ} \mathrm{C}$.

\section{Compounds and enzymes}

The TLR4 signaling inhibitor (TAK-242; CLI-095) was purchased from Invivogen. It was dissolved at a concentration of $1 \mathrm{mg} / \mathrm{ml}$ in dimethyl sulfoxide and then $10 x$ diluted with assay medium. For each replicate experiment, the stock concentration was freshly diluted to $5 \mu \mathrm{M}$. RNase $\mathrm{A}$ was purchased from Promega and dissolved at a concentration of $4 \mathrm{mg} / \mathrm{ml}$ in TE buffer. The RNase inhibitor (RNasin ${ }^{\circledR}$ Ribonuclease Inhibitor) was purchased from Promega and was ready to use.

\section{Bacteria and bacterial cell wall components}

Different bacterial cell wall components, i.e. LPS of Escherichia coli 0111:B4, Klebsiella pneumoniae, Pseudomonas aeruginosa, Serratia marcescens, and LTA from Bacillus subtilis, and PG from Bacillus subtilis, Micrococcus luteus and Staphylococcus aureus, were purchased 
from Sigma-Aldrich. Klebsiella pneumoniae, Pseudomonas aeruginosa, Acinetobacter Iwoffii, Corynebacterium amycolatum, Cutibacterium (formerly Propionibacterium) acnes and Staphylococcus aureus belonged to the collection of the Laboratory Molecular Bacteriology (KU Leuven, Rega Institute) or were a kind gift of Prof. K. Lagrou (Laboratory Medicine, University Hospital Leuven). Bacteria were cultured overnight in $5 \mathrm{ml}$ Tryptic Soy Broth (BD) or Brain Heart Infusion (BD) medium at $37^{\circ} \mathrm{C}$ and $180 \mathrm{rpm}$. These precultures were 1:20 to 1:50 diluted in $50 \mathrm{ml}$ medium and further incubated until an OD of 0.7-1 was reached. Afterwards, cultures were incubated at $60^{\circ} \mathrm{C}$ in a shaking water bath for $20 \mathrm{~min}$ and were subsequently centrifuged at $1500 \mathrm{~g}$. Cell pellets were washed and finally resuspended in sterile saline. Inactivation of the bacteria was checked by plating them on Tryptic Soy agar (BD) plates.

\section{Determination of viral loads after incubation with bacteria or bacterial cell components}

Virus inoculum $\left(10^{6} \mathrm{PFU} / \mathrm{ml}\right)$ was pre-incubated at $37^{\circ} \mathrm{C}$ for 1 or $4 \mathrm{~h}$ with an equal volume of one of the bacterial cell wall components (at a final concentration of $500 \mu \mathrm{g} / \mathrm{ml}$ for LPS of $K$. pneumoniae, P. aeruginosa and S. marcescens, and $1 \mathrm{mg} / \mathrm{ml}$ for LPS E. coli, LTA B. subtilis and PG from B. subtilis, M. luteus and S. aureus) or $10^{10}$ heat-inactivated bacterial cells $/ \mathrm{ml}$ from $K$. pneumoniae, P. aeruginosa, A. Iwoffii, C. amycolatum, C. acnes and S. aureus. Control samples were prepared by mixing the same virus inoculum with $2 \%$ assay medium. At the end of the incubation time, the infectious virus progeny in the virus/bacterial cell wall component, virus/bacteria mixtures or the control were quantified by end-point titration on Vero cells.

Briefly, cells were seeded in 96-well microtiter plates (at a density of $2.5 \times 10^{4}$ cells/well for Vero cells, $2 \times 10^{4}$ cells/well for Vero E6 cells and $1.2 \times 10^{4}$ cells/well for CRL-2522 cells) and were allowed to adhere overnight. The next day, 3 parallel 10 -fold serial dilutions of the virus/bacterial component or virus/bacteria mixtures were prepared in the plates. After the specified incubation time for each virus ( 3 days in case of alphaviruses, 7 days for flaviviruses), the cells were examined microscopically for virus-induced cytopathogenic effect (CPE). A well was scored positive if any traces of virus-induced CPE were observed compared to the uninfected controls. The $\mathrm{TCID}_{50} / \mathrm{ml}$ was calculated using the method of Reed and Muench (23) and is defined as the virus dose that would infect $50 \%$ of the cell cultures. Limits of quantification (LOQs) were determined as the lowest viral loads that could be quantified using this method. 
For the experiment with the TLR4-inhibitor, virus/LPS mixtures, which were pre-incubated at $37^{\circ} \mathrm{C}$ for $1 \mathrm{~h}$, were added to the cells (Vero or skin fibroblasts), where after the TLR4-inhibitor TAK-242 was added at an end concentration of $5 \mu \mathrm{M}$.

To study the effect on intra- and extracellular viral RNA levels, Vero cells were pre-seeded at $2.5 \times 10^{4}$ cells/well in a 96-well plate (BD Falcon). The next day, after $4 \mathrm{~h}$ of pre-incubation, cells were infected in triplicate with either a virus/bacterial cell wall component mixture (as described above) or control mixture. At $2 \mathrm{~h}$ post-infection ( $\mathrm{pi}$ ), the inoculum was removed and cells were washed three times with assay medium. At $24 \mathrm{~h}$ pi, extracellular viral RNA was extracted using the NucleoSpin RNA virus kit (Macherey-Nagel) and intracellular viral RNA using the E.Z.N.A Total RNA Kit I (Omega Bio-tek), according to the manufacturer's protocols. Viral RNA levels were quantified by quantitative reverse transcription PCR (qRT-PCR).

\section{Immunofluorescence assay}

Skin fibroblasts $\left(2.4 \times 10^{4}\right.$ cells/well) were seeded in 8-well chamber slides (Ibidi) that were pretreated with poly-L-lysin (Merck) to improve cell attachment. The next day, cells were preincubated with TLR4 inhibitor (TAK-242; $5 \mu \mathrm{M}$ ) for $1 \mathrm{~h}$ and exposed to a mixture of LPS of $K$. pneumoniae (end concentration of $50 \mu \mathrm{g} / \mathrm{ml}$ ) and TAK-242 (end concentration of $5 \mu \mathrm{M}$ ) for 2 h. Controls without LPS or without TAK-242 were processed alongside. After exposure, cells were fixed with $3.7 \%$ formaldehyde (Sigma-Aldrich) for $20 \mathrm{~min}$. The day after, cells were permeabilized with $0.5 \%$ Triton X-100 (Sigma-Aldrich) for $10 \mathrm{~min}$ and were blocked with 3\% bovine serum albumin (BSA; Sigma) for 30 minutes, where after cells were stained with NF-KB p65 antibody (1:200 dilution in 1\% BSA in PBS; Santa Cruz Biotechnology) in the dark for $1 \mathrm{~h}$. Goat anti-mouse IgG Alexa Fluor 488 (1:500 dilution in 1\% BSA in PBS; Invitrogen) was used as the secondary antibody. Nuclei were stained with Hoechst (1:1000 dilution in PBS; Invitrogen) in the dark for $20 \mathrm{~min}$. Cellular localization of NF-KB was determined with a Leica TCS SP5 laser scanning confocal microscope (Leica Microsystems), using a HCX PL APO 63.0x (NA:1.20) water immersion lens.

\section{Virucidal assay}

Virus $\left(10^{6} \mathrm{PFU} / \mathrm{ml}\right)$ was pre-incubated at $37^{\circ} \mathrm{C}$ with LPS of $K$. pneumoniae or $P$. aeruginosa (at a final concentration of $500 \mu \mathrm{g} / \mathrm{ml}$ ) or $2 \%$ assay medium for $1 \mathrm{~h}$, after which $1 \mu$ l RNase A (4 $\mathrm{mg} / \mathrm{ml}$, Promega) was added to the reaction mixture. As a positive control, extracted viral RNA 
was treated with RNase A. After $1 \mathrm{~h}$ incubation at $37^{\circ} \mathrm{C}, 1 \mu \mathrm{L}$ of RNAse inhibitor $(40 \mathrm{U} / \mu \mathrm{l}$, Promega) was added to stop the reaction. The viral RNA in each sample was extracted using the NucleoSpin RNA virus kit (Macherey-Nagel) and quantified by qRT-PCR.

\section{Quantitative reverse transcription PCR (qRT-PCR)}

The sequences of primers used in qRT-PCR were for CHIKV: forward primer: 5'CCGACTCAACCATCCTGGAT-3', reverse primer: 5'- GGCAGACGCAGTGGTACTTCCT-3' (24); for SFV: forward primer: 5'-GCAAGAGGCAAACGAACAGA-3', reverse primer: 5'GGGAAAAGATGAGCAAACCA-3' (25); for ZIKV: forward primer: 5'-CCGCTGCCCAACACAAG-3', reverse primer: 5'-CCACTAACGTTCTTTTGCAGACAT-3' (26). The probe sequences were 5'FAM-TCCGACATCATCCTCCTTGCTGGC-TAMRA-3' (CHIKV) (24) and 5'-FAM-AGCCTACCT-ZENTGACAAGCAATCAGACACTCAA-IABkFQ-3' (ZIKV) (26). One-step, quantitative RT-PCR was performed for CHIKV and ZIKV in a total volume of $25 \mu \mathrm{l}$, containing $13.94 \mu \mathrm{l}$ RNase free water (Promega), $6.25 \mu \mathrm{l}$ master mix (Eurogentec), $0.375 \mu \mathrm{l}$ of forward primer, $0.375 \mu \mathrm{l}$ of reverse primer [final concentration of each primer: $150 \mathrm{nM}$ (CHIKV); $900 \mathrm{nM}$ (ZIKV)], $1 \mu$ l of probe [final concentration: $400 \mathrm{nM}$ (CHIKV); $200 \mathrm{nM}$ (ZIKV)], $0.0625 \mu \mathrm{l}$ reverse transcriptase (Eurogentec) and $3 \mu \mathrm{l}$ RNA sample. For SFV, the reaction mixture $(20 \mu \mathrm{l})$ contained: $4.75 \mu \mathrm{l}$ RNAse free water, $10 \mu \mathrm{l}$ SYBR green master mix (Bio-Rad), $1 \mu$ l of forward primer, $1 \mu$ of reverse primer (final concentration of each primer $500 \mathrm{nM}$ ), $0.25 \mu$ l reverse transcriptase (Eurogentec) and $3 \mu \mathrm{l}$ sample. The qRT-PCR reaction was performed with the Applied Biosystems 7500 Fast Real-Time PCR System using the following conditions for CHIKV and ZIKV: $30 \mathrm{~min}$ at $48^{\circ} \mathrm{C}, 10 \mathrm{~min}$ at $95^{\circ} \mathrm{C}$, followed by 40 cycles of $15 \mathrm{~s}$ at $95^{\circ} \mathrm{C}$ and $1 \mathrm{~min}$ at $60^{\circ} \mathrm{C}$. For SFV, the following conditions were used: $10 \mathrm{~min}$ at $50^{\circ} \mathrm{C}, 3 \mathrm{~min}$ at $95^{\circ} \mathrm{C}$, followed by 40 cycles of $15 \mathrm{~s}$ at $95^{\circ} \mathrm{C}$ and $30 \mathrm{~s}$ at $60^{\circ} \mathrm{C}$.

For quantification, standard curves were generated each run using 10-fold dilutions of cDNA of CHIKV nsP1 and SFV nsP3 or viral RNA isolated from the ZIKV Suriname virus stock (virucidal assay) or a synthesized gene block containing ZIKV E protein (assay to determine effect of LPS on viral RNA levels). Limits of detection (LODs) were determined as the lowest viral loads that could be detected by the qRT-PCR assay in $95 \%$ of experiments (27).

Transmission electron microscopy (TEM) 
SFV $\left(6 \times 10^{8} \mathrm{PFU} / \mathrm{ml}\right)$ was pre-incubated at $37^{\circ} \mathrm{C}$ with LPS of $K$. pneumoniae or $P$. aeruginosa (final concentration of $500 \mu \mathrm{g} / \mathrm{ml}$ ) or LPS of E. coli (final concentration of $1 \mathrm{mg} / \mathrm{ml}$ ) for $1 \mathrm{~h}$. Preincubation of SFV with LPS of S. marcescens (final concentration of $500 \mu \mathrm{g} / \mathrm{ml}$ ) was performed for different incubation times $(0,5,10,15,20,25,30$ min or $1 \mathrm{~h})$. SFV was pre-incubated at $37^{\circ} \mathrm{C}$ with heat-inactivated $K$. pneumoniae or $S$. aureus bacteria $\left(10^{10} \mathrm{cells} / \mathrm{ml}\right)$ for $1 \mathrm{~h}$. Viruses were inactivated by glutaraldehyde (Electron Microscopy Sciences; final concentration 1.25\%) at room temperature for 30 min. Formvar-carbon coated 400-mesh copper grids (Ted Pella) were first glow-discharged to improve adsorption efficiency, and then placed on $20 \mu \mathrm{l}$ of sample for $5 \mathrm{~min}$, after which excess of sample was removed by blotting on filter paper. In order to increase virus density on the grid, grids were further incubated 4 times for 1 minute with intermittent blotting. Subsequently, grids were washed by contact with 2 drops of milliQ water, negatively stained with $20 \mu \mathrm{l}$ of $1 \%$ uranyl acetate (Electron Microscopy Sciences) for 1 min, after which excess was removed using filter paper. After drying, the grids were examined using a transmission electron microscope (JEOL JEM1400), operated at $80 \mathrm{kV}$ and equipped with an EMSIS Quemesa $11 \mathrm{Mpxl}$ camera. The number of viruses that could be detected at a magnification of $4000 \mathrm{x}$ was counted for each incubation time at 6 randomly picked positions on the grid (each position represented a surface of $132 \mu \mathrm{m}^{2}$ of the grid).

\section{Ex vivo skin culturing}

Mouse skin was collected under the approval of the Ethical Committee of the University of Leuven (licenses P071/2019, M020/2020) following institutional guidelines approved by the Federation of European Laboratory Animal Science Associations (FELASA). In-house-bred female, $>20$ weeks old AG129 mice (deficient in both IFN- $\alpha / \beta$ and IFN- $\gamma$ receptors) were sacrificed by intraperitoneal injection of Doléthal (Vétoquinol). The back of the mice was shaven and dorsal skin was collected and immediately covered in Dulbecco's Modified Eagle Medium (DMEM; Gibco) supplemented with 10\% FBS, 1\% penicillin/streptomycin (Gibco) and $0.1 \%$ gentamycin (Sigma) on ice. Next, subcutaneous adipose tissue was removed and the dorsal skin was cut into pieces of approximately $1 \mathrm{~cm}^{2}$. After a wash step in PBS, skin samples were individually placed (epidermis-side up) in a 12-well (BD Falcon) plate and incubated in supplemented DMEM at $37^{\circ} \mathrm{C}$ until infection. 
SFV $\left(1 \times 10^{4} \mathrm{PFU} / \mathrm{ml}\right)$ was pre-incubated with an equal volume of LPS of $K$. pneumoniae, $P$. aeruginosa and S. marcescens (at a final concentration of $500 \mu \mathrm{g} / \mathrm{ml}$ ) at $37^{\circ} \mathrm{C}$ for $4 \mathrm{~h}$. Control samples were prepared by adding an equal volume of $2 \%$ assay medium to the SFV inoculum. The SFV-LPS mixtures were added to the skin explants and after $2 \mathrm{~h}$ of incubation at $37^{\circ} \mathrm{C}$, the inoculum was removed. Skin explants were washed 3 times in PBS and were again incubated in supplemented DMEM. At day 2 pi, the skin tissue was transferred to a Precellys tube (Bertin Instruments) containing $2 \%$ assay medium. Skin tissues were homogenized in two cycles at $7600 \mathrm{rpm}$ with a $20 \mathrm{~s}$ interval, using an automated homogenizer (Precellys24, Bertin Instruments). After centrifugation (15000 rpm, $15 \mathrm{~min}, 4^{\circ} \mathrm{C}$ ), supernatant was collected and infectious virus was quantified by end-point titrations.

\section{Statistics}

All data were analysed using Graphpad Prism 8.3.1. The results of the virucidal assays were statistically analysed using a nonparametric Two-way ANOVA with Sidak's correction for multiple comparisons. The effect of LPS on viral RNA levels was analysed using the Mann Whitney $U$ test (nonparametric t-test). All other results were analysed by Kruskal-Wallis tests (nonparametric One-way ANOVA). Statistical significance threshold was assessed at $p$ values of $<0.05$. Statistical details are described in the figure legends. 


\section{Results}

\section{CHIKV infection is reduced by certain components of the bacterial cell wall}

To study the effect of bacterial cell wall components on arbovirus infectivity, different cell wall structures (LPS of K. pneumoniae, and LTA or PG of B. subtilis) were incubated with CHIKV at $37^{\circ} \mathrm{C}$ and viral infectivity was determined by end-point titration on Vero cells. LPS of $\mathrm{K}$. pneumoniae completely blocked viral infectivity, whereas a modest inhibitory effect of $\sim 1.5$ $\log _{10}$ reduction was observed with PG of $B$. subtilis (Fig. 1A). LTA of $B$. subtilis resulted in less than $1 \log _{10}$ reduction in infectious virus levels. The complete disruption of CHIKV infectivity by LPS of $K$. pneumoniae was also confirmed at viral RNA level, both intracellularly and in the supernatant (Supplemental Fig. 1A). As the structures of LPS can significantly differ between different bacteria and as the preparation method of PG might affect the composition, we explored whether the observed reduction in virus infectivity by LPS and PG was shared by LPS/PG from other bacterial species. To this end, the effect of a panel (Table 1) of LPS from Gram-negative bacteria (P. aeruginosa, E. coli, S. marcescens) and PG of Gram-positive bacteria (S. aureus, M. luteus) on CHIKV infectivity was evaluated (Fig. 1B). Clear differences in the ability to decrease CHIKV infection in Vero cells were observed between LPS and PG of different bacterial species: incubation with most LPS and PG resulted only in a modest inhibitory effect (1-2 $\log _{10}$ reduction), whereas no effect was observed with PG of S. aureus and $M$. luteus ( $<1 \log _{10}$ reduction). These data suggest that the reduction of CHIKV infectivity is not widely shared by LPS and PG molecules of all bacteria.

\section{Certain LPS and PG reduce the infectivity of different alphaviruses and flaviviruses}

To find out whether this inhibitory effect is a broad-spectrum phenomenon amongst arboviruses, the panel of bacterial cell wall components was evaluated against arboviruses of two virus families: SFV, SINV and MAYV of the Alphavirus genus (Togaviridae) and ZIKV and YFV of the Flavivirus genus (Flaviviridae). Comparable results were observed for most alphaviruses (Fig. 2A) and flaviviruses (Fig. 2B), except for PG of B. subtilis and S. aureus, which were able to completely inhibit ZIKV infection (Fig. 2B) and LPS of S. marcescens which inhibited SFV, SINV (Fig. 2A) and ZIKV replication (Fig. 2B) in Vero cells. Furthermore, LPS of $K$. pneumoniae could not completely reduce MAYV (Fig. 2A) and ZIKV (Fig. 2B) infectivity, whereas LPS of $P$. aeruginosa was able to inhibit (almost) completely SFV and SINV infectivity 
in Vero cells ( $\sim 4$ and $\sim 3.5 \log _{10}$ reduction in $\mathrm{TCID}_{50} / \mathrm{ml}$, respectively) (Fig. $2 \mathrm{~A}$ ). The decrease in flavivirus infectivity by LPS of $K$. pneumoniae was also confirmed by the substantially reduced ZIKV RNA levels (intracellular and extracellular) following incubation with LPS of $K$. pneumoniae (Supplemental Fig. 1B).

\section{Specific LPS and PG reduce alphavirus infectivity in human skin fibroblasts and ex vivo cultured mouse skin}

To investigate whether virus inhibition would also be observed in other cell types, we assessed CHIKV infectivity after incubation with LPS or PG in human skin fibroblasts. LPS of $K$. pneumoniae completely blocked CHIKV infectivity in skin fibroblasts (Fig. 3A), similar to what was observed in Vero cells. For LPS and PG of other bacterial species, there were minor variations in the reductions in infectivity between Vero cells and skin fibroblasts. However, LPS of S. marcescens completely blocked CHIKV infectivity in skin fibroblasts, in contrast to the effect observed in Vero cells ( $2 \log _{10}$ decrease).

Next, we determined the effect of LPS on viral infectivity in ex vivo cultured mouse skin. First, the replication kinetics of SFV were defined in the skin explants (Supplemental Fig. 2), showing that high viral titers could be reached at day 2 and day 3 pi. Next, we incubated SFV with different LPS and determined the infectious virus titer in the skin. Similar to what was observed in vitro (Fig. 2), LPS of $K$. pneumoniae, P. aeruginosa and S. marcescens (almost) completely inhibited SFV infectivity (Fig. 3B).

\section{Alphavirus and flavivirus infectivity is reduced by specific bacteria}

We next evaluated whether complete bacteria could also affect the infectivity of arboviruses. To this end, we selected a panel of gram-negative (K. pneumoniae, P. aeruginosa and A. Iwoffii) and gram-positive bacteria (S. aureus, C. amycolatum, C. acnes) (Table 1). The Gram-positive Staphylococcus, Corynebacterium and Cutibacterium spp. are among the most abundant colonizers of the skin (5). The most reported Gram-negative skin bacteria are the Acinetobacter spp. $(28,29)$. After inactivation of the bacteria by heating, viruses (CHIKV, SFV and ZIKV) were incubated with these bacterial species at $37^{\circ} \mathrm{C}$ for $4 \mathrm{~h}$. A modest inhibitory effect was observed with $K$. pneumoniae, $P$. aeruginosa and $A$. Iwoffii on CHIKV, and with $K$. pneumoniae, P. aeruginosa, A. Iwoffii, C. amycolatum and C. acnes on SFV (Fig. 4A). For ZIKV on the other hand, the inhibition by $K$. pneumoniae, $P$. aeruginosa and $A$. Iwoffii was more 
pronounced $\left(\sim 2-2.5 \log _{10}\right.$ reduction in $\left.T C I D_{50} / \mathrm{ml}\right)$. To investigate whether the heatinactivation procedure could be the reason for the differences between the effects by LPS and the bacteria, LPS of K. pneumoniae was subjected to the same heating procedure. Following incubation with heated LPS, CHIKV infectivity was still completely reduced (Fig. 4B), confirming that LPS is a heat-stable cell wall component $(15,30)$.

\section{Disruption of virus infectivity is time- and dose-dependent}

To determine how fast the inhibition of infection occurs, CHIKV, SFV and ZIKV were incubated with LPS of $K$. pneumoniae at $37^{\circ} \mathrm{C}$ for $0 \mathrm{~min}, 10 \mathrm{~min}, 30 \mathrm{~min}, 1 \mathrm{~h}$ or $4 \mathrm{~h}$ (Fig. 5A). LPS of $K$. pneumoniae was selected for this purpose, as this molecule was the most potent of the evaluated panel of cell wall components. For both alphaviruses, a short incubation time with LPS was sufficient to achieve complete inhibition (CHIKV: $30 \mathrm{~min}$; SFV: $10 \mathrm{~min}$ ). For ZIKV on the other hand, a fast drop in infectivity was initially observed $\left(\sim 3 \log _{10}\right)$, but at least 60 min of incubation was required to result in a maximal inhibition of $\sim 3.5 \log _{10}$ in $T C I D_{50} / \mathrm{ml}$.

To determine the minimum inhibitory concentration of LPS of $K$. pneumoniae, serial dilutions (from 0-500 $\mu \mathrm{g} / \mathrm{ml}$ ) were incubated with CHIKV and infectivity was determined by end-point titration on Vero cells. The effective concentration that inhibit $90 \%$ virus-induced cell death (EC90) of LPS of $K$. pneumoniae was $167 \mu \mathrm{g} / \mathrm{ml}$ and a concentration of $250 \mu \mathrm{g} / \mathrm{ml}$ was necessary to completely block the virus (Fig. 5B).

\section{Is the reduced virus infectivity cell- or virus-dependent?}

The reduction of virus infectivity might be due to a direct interaction between LPS and the virus or by an effect of LPS on cellular immune pathways (or a combination of both). Comparable effects in skin fibroblasts and Vero cells were observed (Fig. 1 and 3A), except for LPS of S. marcescens, which caused a more prominent inhibition of CHIKV infection in skin fibroblasts. Therefore, we pre-incubated LPS of S. marcescens and K. pneumoniae with cells (Vero cells or skin fibroblasts) or virus (CHIKV) for $1 \mathrm{~h}$ and determined viral infectivity by endpoint titration (Fig. 6A). LPS of K. pneumoniae was enclosed as well, since this was the only LPS that could inhibit all tested viruses in this study. For both LPS, inhibition of CHIKV infectivity was more pronounced when LPS was pre-incubated with virus, both in Vero cells and in skin fibroblasts, suggesting that the main inhibitory mechanisms is due to a direct interaction of LPS with the viral particle. 
It has been described that bacteria can activate an LPS-dependent Toll-like receptor 4 (TLR4) immune pathway, resulting in an antiviral effect (14). TLR4 is expressed in human skin fibroblasts (31) and LPS can induce the activation of the TLR4-NF-KB immune pathway in mouse fibroblasts (32). To investigate whether the observed viral inhibition in skin fibroblasts might be due to the stimulation of this immune pathway by LPS, we first confirmed the activation of TLR4 by LPS in human skin fibroblasts by immunofluorescence staining of NF-kB. Upon incubation with LPS, the NF-KB protein was translocated from the cytoplasm to the nucleus (Fig. 6B panel 2), proving that the skin fibroblasts indeed express TLR4. The TLR4 inhibitor TAK-242 was able to block the activation of the TLR4-NF-KB pathway in the skin fibroblasts, since the fluorescent signal was only visible in the cytoplasm (Fig 6B panel 3). Finally, we assessed viral infectivity upon incubation with LPS in the presence of TAK-242. TAK242 alone had no adverse effect on CHIKV infection in the skin fibroblasts (Fig. 6C). When added to cell cultures infected with LPS pre-incubated virus, TAK-242 did not affect the inhibitory effect of LPS on CHIKV infection (Fig. 6C), suggesting that the effect on viral infectivity is not due to TLR4 activation by LPS.

\section{LPS exerts a virucidal effect on alphaviruses and flaviviruses}

To determine how virus infectivity is reduced by incubation with LPS, virucidal assays were performed with two alphaviruses (CHIKV and SFV) and one flavivirus (ZIKV). Incubation of CHIKV virus particles with LPS of $K$. pneumoniae in addition of RNase resulted in a decrease of $\sim 4 \log _{10}$ in viral genome copies, whereas incubation with LPS of $P$. aeruginosa did not (Fig. 7A). This was in line with our previous experiments measuring viral infectivity (Fig. 1B). On the other hand, SFV RNA levels were reduced with $\sim 2.5 \log _{10}$ after incubation with LPS of both bacteria and RNase (Fig. 7B). For ZIKV, we noticed a more modest effect: viral RNA levels were reduced to a lesser extent after incubation with LPS, compared to the positive RNA control (Fig. 7C).

To confirm that the virucidal effect was caused by a direct interaction between LPS and the virus, we imaged SFV particles in the absence and presence of LPS by TEM. LPS of $K$. pneumoniae, P. aeruginosa and S. marcescens were selected as these completely inhibited SFV infectivity in cell culture (Fig. 2A). The structures of LPS of $K$. pneumoniae and $P$. aeruginosa were difficult to distinguish from virus particles as the LPS consisted of multiple globular shapes (Supplemental Fig. 3A-D). LPS of S. marcescens on the other hand had a 
filamentous structure, which was easier to distinguish from virus particles (Supplemental Fig. 4A). LPS of E. coli was included as a negative control (Supplemental Fig. 4C-D). After incubation with LPS of $E$. coli for $1 \mathrm{~h}$, the structure of the SFV particles was similar to the structure of untreated viruses (Fig. 8A). In contrast, upon incubation with LPS of S. marcescens, the morphology of the virus particles changed with longer incubation times (Fig. 8A). In addition, the number of viruses detected at a magnification of $4000 \mathrm{x}$ decreased with longer incubation times (Fig. 8B). Following 30 minutes of incubation, no viruses could be detected anymore (Supplemental Fig 4B).

Next, we determined whether a similar effect was observed with heat-inactivated bacteria. After $1 \mathrm{~h}$ of incubation with $K$. pneumoniae, virus particles were absent in the TEM images (Supplemental Fig. 5A), whereas virus particles were still present after incubation with $S$. aureus (Supplemental Fig 5B). The TEM data thus strengthened our hypothesis that specific LPS or bacteria exert a virucidal effect on alphaviruses and flaviviruses. 


\section{Discussion}

Complex interplays between viruses and host microbiota have recently gained more interest. Especially viruses that colonize the gastrointestinal tract have been studied the most due to the vast microbial community at the site of the initial virus infection (33). Currently, little research is performed regarding the role of host microbiota in arbovirus infectivity. Since arboviruses are first inoculated in the skin during the bite of an arthropod, the purpose of this research was to characterize interactions and involved mechanisms between arboviruses and the microbiota that colonize the skin. First, we tested the effect of different bacterial cell wall components (LPS, PG and LTA) on alphavirus and flavivirus infectivity. Our data indicated that not all tested bacterial cell wall structures were equally potent in inhibiting virus infectivity. Especially between the tested LPS, major differences were detected, ranging from no antiviral activity (e.g. LPS E. coli) to a complete inhibitory effect (e.g. LPS of $K$. pneumoniae). The structural variability of LPS is generally attributed to the polysaccharide part, particularly to the O-antigen (34). Furthermore, it has also been described that subtle chemical variations in the lipid A structure of LPS can cause drastic changes in LPS activity (35), potentially resulting in differential potencies to inhibit viral replication. Moreover, there were differences in potency of the same LPS/PG against different viruses. The general trend was the inhibitory effect of LPS of $K$. pneumoniae (on all tested viruses), LPS of $P$. aeruginosa (except on CHIKV) and LPS of S. marcescens (on SFV, SINV and ZIKV). All these bacteria are Gram-negative Proteobacteria, while the human skin (dermis and epidermis) is believed to be quantitatively dominated by the Gram-positive cutibacteria, corynebacteria (both Actinobacteria), and Staphylococcus species (Firmicutes) $(28,29,36)$. Nevertheless, approximately $23 \%$ of the bacteria found on the skin are Gram-negative Proteobacteria or Bacteriodetes (37), whereby P. aeruginosa (a Proteobacterium used in our panel) was detected in human skin samples of the forearm (28). Furthermore, a more diverse population of bacteria resides in dry skin regions $(5,8)$, with a greater prevalence of Gram-negative $\beta$-Proteobacteria and Flavobacteriales (37).

The effect of heat-inactivated bacteria on virus infectivity was investigated as well. Several skin bacteria ( $C$. amycolatum, $C$. acnes, S. aureus and $A$. Iwoffii) were evaluated, as well as $K$. pneumoniae and $P$. aeruginosa. The effect of the complete bacteria was less pronounced, compared to the effect of LPS: only for ZIKV was there a clear inhibitory effect of $A$. Iwoffii, $K$. 
pneumoniae and $P$. aeruginosa on infectivity. The Gram-positive skin bacteria resulted in a modest viral inhibition, although the magnitude of inhibition was similar to the inhibition previously observed for influenza virus (15) by some bacterial isolates. In contrast, the Gramnegative skin bacterium $A$. Iwoffi resulted in the highest inhibitory effect, which suggest that mainly Gram-negative bacteria reduce viral infectivity. Similar effects were observed with cell wall components (Fig. 2): LPS of Gram-negative K. pneumoniae, P. aeruginosa and $S$. marcescens completely inhibited viral infectivity, whereas most of the PG of Gram-positive bacteria did not exert an inhibitory effect. A possible reason for the more modest inhibition seen with the heat-inactivated bacteria could be that the concentrations of purified LPS used in our assay, were much higher than the concentrations LPS present in complete bacteria. For our assays, we used a concentration of $500 \mu \mathrm{g} / \mathrm{ml}$ LPS, based on the dose-dependent effect of LPS. To the best of our knowledge, it has not been determined yet which concentrations of LPS are representative for the human skin. LPS concentrations can widely differ between organs: for example for the gut, an estimated concentration of $1 \mathrm{~g}$ of LPS has been reported, resulting in $\mathrm{mg} / \mathrm{ml}$ concentrations, whereas only $10-20 \mathrm{pg} / \mathrm{ml}$ has been detected in plasma of healthy volunteers (38). Therefore, further studies concerning the concentrations of LPS in the human skin are necessary to determine the physiological relevance of our research. Furthermore, it is possible that the purified, commercially available LPS can have other effects than the natural cell wall-associated form in the complete, heat-inactivated bacteria, where the lipid A part is embedded in the membrane, hidden from the surface. Another reason could be that the used heat-inactivation procedure may have altered the LPS molecules or the structure of the outer membrane that encloses these molecules. However, LPS has been shown to be heat-stable $(15,30)$ and this was confirmed in our experiment by the fact that the inhibitory effect of LPS was not lost after the heating procedure.

We next determined whether the reduced virus infectivity by LPS was due to a cell-dependent effect. Skin fibroblasts were included, as they are the first cells that are infected by alphaviruses after the arthropod bite (39) and it is very likely that they are also infected in the early stages of flavivirus infections $(40,41)$. Viral infectivity was only significantly reduced when LPS was pre-incubated with the virus and not when LPS was pre-incubated with the cells, suggesting that the viral inhibition is not due to a cell-dependent effect. A well-characterized cellular interaction of LPS is the activation of Toll-like receptor 4 , resulting in increased innate 
immunity and triggering inflammation and adaptive immune responses (35). To exclude that the viral inhibition was caused by binding of LPS to TLR4, which subsequently activates the TLR4 immune pathway, a TLR4 antagonist was added. In the presence of the TLR4 inhibitor, a similar reduction in viral infectivity was observed by LPS, indicating that the inhibitory effect was not due to the binding and activation of TLR4. Together with other data of this study (Fig. 6), these results suggested that LPS directly interacted with alphaviruses and flaviviruses. We showed that disruption of viral infectivity was partially due to a virucidal effect: there was a decrease in viral RNA when LPS was incubated with the virus particles. This effect was clearly smaller with the flavivirus ZIKV, compared to alphaviruses CHIKV and SFV. To further confirm the hypothesis of a direct effect between alphaviruses and bacteria, SFV particles were imaged by TEM. Our data suggested that disruption of the virus occured upon incubation of SFV with LPS of S. marcescens and heat-inactivated K. pneumoniae bacteria, whereas after incubation with LPS of E. coli and heat-inactivated S. aureus, intact virus particles were clearly visible, confirming our previous titration data (Fig. $2 \mathrm{~A}$ and $3 \mathrm{~A}$ ). A comparable direct effect of LPS on the virus particle has been determined before for influenza virus by TEM (15). Upon incubation with LPS for $20 \mathrm{~min}$, it became difficult to detect the virus particles, since their structure had dramatically changed. Therefore, it is possible that the structures we considered as viruses, were in fact LPS- or bacteria-related structures rather than disrupted viruses.

In general, we determined an inhibitory trend of specific bacterial cell wall components on arbovirus infectivity in vitro. These results are in line with recently published in vivo data (21, 22), which showed an aggravated arbovirus infection upon depletion of the host microbiome by administering antibiotics. These mouse studies confirmed that oral antibiotic treatment reduced bacterial colonization and altered bacterial populations in the faeces. Furthermore, antibiotics reduced host immune responses. A decrease in CD8+ T cells was measured in mice treated with antibiotics and infected with flaviviruses (WNV, DENV, ZIKV) (21). In addition, a decrease of type I IFN production and monocyte interferon stimulating gene expression due to the perturbation of the intestinal microbiome by antibiotic treatment resulted in enhanced alphavirus (CHIKV) infection (22). As mice were orally treated in these studies, the antibiotics affected the gut microbiome and caused a systemic effect. Until now, nothing was known about interactions between arboviruses and the host skin microbiota at the inoculation site. 
bioRxiv preprint doi: https://doi.org/10.1101/2021.05.07.443110; this version posted May 7, 2021. The copyright holder for this preprint (which was not certified by peer review) is the author/funder, who has granted bioRxiv a license to display the preprint in perpetuity. It is made available under aCC-BY-NC-ND 4.0 International license.

Our in vitro data on the direct interaction between host (skin) microbiota and viruses are a first step towards elucidation of this knowledge gap. 


\section{Acknowledgments}

We thank Elke Maas for excellent technical assistance. We thank Prof. K. Lagrou (UZ Leuven) for providing bacterial isolates and Prof. C. Drosten (Charité - Universitätsmedizin Berlin) for providing the CHIKV 899 strain. We thank the European virus archive, EVAg, supported by the European Union's Horizon 2020 research and innovation programme under grant agreement No 871029, for providing MAYV TC625 and ZIKV SL1602, Suriname. We thank Dr. Els Vanstreels and Dr. Maarten Jacquemyn for their help with the set-up of the confocal fluorescence microscope.

\section{Funding}

This research was funded by a ZAP starting grant to LD by KU Leuven (STG/19/008). SJ is a fellow of the "Fund for Scientific Research" Flanders (FWO). 


\section{References}

1. Pingen M, Schmid M, Harris E, McKimmie C. 2017. Mosquito Biting Modulates Skin Response to Virus Infection. Trends Parasitol.

2. Gould E, Pettersson J, Higgs S, Charrel R, de Lamballerie X. 2017. Emerging arboviruses: Why today? One Heal 4.

3. Wilder-Smith A, Gubler DJ, Weaver SC, Monath TP, Heymann DL, Scott TW. 2017. Epidemic arboviral diseases: priorities for research and public health. Lancet Infect Dis 17:e101-e106.

4. Weaver SC, Charlier C, Vasilakis N, Lecuit M. 2018. Zika, Chikungunya, and Other Emerging Vector-Borne Viral Diseases. Annu Rev Med 69:395-408.

5. Grice EA, Segre JA. 2011. The skin microbiome. Nat Rev Microbiol 9:244-253.

6. Nakatsuji T, Chiang H, Jiang SB, Nagarajan H, Zengler K, Gallo RL. 2013. The microbiome extends to subepidermal compartments of normal skin. Nat Commun 4.

7. Ross AA, Rodrigues Hoffmann A, Neufeld JD. 2019. The skin microbiome of vertebrates. Microbiome 7.

8. Byrd AL, Belkaid Y, Segre JA. 2018. The human skin microbiome. Nat Rev Microbiol 16:143-155.

9. Domínguez-Díaz C, García-Orozco A, Riera-Leal A, Padilla-Arellano JR, Fafutis-Morris M. 2019. Microbiota and Its Role on Viral Evasion: Is It With Us or Against Us? Front Cell Infect Microbiol 9.

10. Robinson CM, Pfeiffer JK. 2014. Viruses and the Microbiota. Annu Rev Virol 1:55-69.

11. Jiang Y, Ye L, Cui Y, Yang G, Yang W, Wang J, Hu J, Gu W, Shi C, Huang H, Wang C. 2017. Effects of Lactobacillus rhamnosus GG on the maturation and differentiation of dendritic cells in rotavirus-infected mice. Benef Microbes 8:645-656.

12. Kawahara T, Makizaki Y, Oikawa Y, Tanaka Y, Maeda A, Shimakawa M, Komoto S, Moriguchi K, Ohno H, Taniguchi K. 2017. Oral administration of Bifidobacterium bifidum G9-1 alleviates rotavirus gastroenteritis through regulation of intestinal 
homeostasis by inducing mucosal protective factors. PLoS One 12.

13. Nahui Palomino RA, Zicari S, Vanpouille C, Vitali B, Margolis L. 2017. Vaginal lactobacillus inhibits HIV-1 replication in human tissues ex vivo. Front Microbiol 8.

14. Shinya K, Okamura T, Sueta S, Kasai N, Tanaka M, Ginting TE, Makino A, Eisfeld AJ, Kawaoka Y. 2011. Toll-like receptor pre-stimulation protects mice against lethal infection with highly pathogenic influenza viruses. Virol J 8.

15. Bandoro C, Runstadler J. 2017. Bacterial Lipopolysaccharide destabilizes influenza virus. mSphere 2:e00267-17.

16. Johnson B, Hage A, Kalveram B, Mears M, Plante J, Rodriguez S, Ding Z, Luo X, Bente D, Bradrick SS, Freiberg AN, Popov V, Rajsbaum R, Rossi S, Russell WK, Menachery VD. 2019. Peptidoglycan-Associated Cyclic Lipopeptide Disrupts Viral Infectivity. J Virol 93:e01282-19.

17. Almand EA, Moore MD, Outlaw J, Jaykus LA. 2017. Human norovirus binding to select bacteria representative of the human gut microbiota. PLoS One 12.

18. Robinson C, Jesudhasan P, Pfeiffer J. 2014. Bacterial lipopolysaccharide binding enhances virion stability and promotes environmental fitness of an enteric virus. Cell Host Microbe 15:36-46.

19. Berger AK, Yi H, Kearns DB, Mainou BA. 2017. Bacteria and bacterial envelope components enhance mammalian reovirus thermostability. PLoS Pathog 13.

20. Kuss SK, Best GT, Etheredge CA, Pruijssers AJ, Frierson JM, Hooper L V., Dermody TS, Pfeiffer JK. 2011. Intestinal microbiota promote enteric virus replication and systemic pathogenesis. Science (80- ) 334:249-252.

21. Thackray LB, Handley SA, Gorman MJ, Poddar S, Bagadia P, Briseño CG, Theisen DJ, Tan Q, Hykes BL, Lin H, Lucas TM, Desai C, Gordon Jl, Murphy KM, Virgin HW, Diamond MS. 2018. Oral Antibiotic Treatment of Mice Exacerbates the Disease Severity of Multiple Flavivirus Infections. Cell Rep 22:3440-3453.

22. Winkler ES, Shrihari S, Hykes BL, Handley SA, Andhey PS, Huang Y-JS, Swain A, Droit L, Chebrolu KK, Mack M, Vanlandingham DL, Thackray LB, Cella M, Colonna M, Artyomov 
MN, Stappenbeck TS, Diamond MS. 2020. The Intestinal Microbiome Restricts Alphavirus Infection and Dissemination through a Bile Acid-Type I IFN Signaling Axis. Cell 182:1-18.

23. Reed LJ, Muench H. 1938. A simple method of estimating fifty percent endpoints. Am J Hyg 27:493-497.

24. Delang L, Segura Guerrero N, Tas A, Quérat G, Pastorino B, Froeyen M, Dallmeier K, Jochmans D, Herdewijn P, Bello F, Snijder EJ, de Lamballerie X, Martina B, Neyts J, van Hemert MJ, Leyssen P. 2014. Mutations in the chikungunya virus non-structural proteins cause resistance to favipiravir (T-705), a broad-spectrum antiviral. J Antimicrob Chemother 69:2770-84.

25. Fragkoudis R, Chi Y, Siu RWC, Barry G, Attarzadeh-Yazdi G, Merits A, Nash AA, Fazakerley JK, Kohl A. 2008. Semliki Forest virus strongly reduces mosquito host defence signaling. Insect Mol Biol 17:647-656.

26. Jacobs S, Delang L, Verbeken E, Neyts J, Kaptein SJF. 2019. A viral polymerase inhibitor reduces zika virus replication in the reproductive organs of male mice. Int J Mol Sci 20.

27. Bustin SA, Benes V, Garson JA, Hellemans J, Huggett J, Kubista M, Mueller R, Nolan T, Pfaffl MW, Shipley GL, Vandesompele J, Wittwer CT. 2009. The MIQE guidelines: Minimum information for publication of quantitative real-time PCR experiments. Clin Chem 55:611-622.

28. Cosseau C, Romano-Bertrand S, Duplan H, Lucas O, Ingrassia I, Pigasse C, Roques C, Jumas-Bilak E. 2016. Proteobacteria from the human skin microbiota: Species-level diversity and hypotheses. One Heal 2:33-41.

29. Bay L, Barnes CJ, Fritz BG, Thorsen J, Restrup MEM, Rasmussen L, Sørensen JK, Hesselvig AB, Odgaard A, Hansen AJ, Bjarnsholt T. 2020. Universal dermal microbiome in human skin. MBio 11:e02945-19.

30. Weinstein JR, Swarts S, Bishop C, Hanisch UK, Möller T. 2008. Lipopolysaccharide is a frequent and significant contaminant in microglia-activating factors. Glia 56:16-26.

31. Yao C, Oh JH, Lee DH, Bae JS, Jin CL, Park CH, Chung JH. 2015. Toll-like receptor family 
members in skin fibroblasts are functional and have a higher expression compared to skin keratinocytes. Int J Mol Med 35:1443-1450.

32. Li X-P, Liu P, Li Y-F, Zhang G-L, Zeng D-S, Liu D-L. 2019. LPS induces activation of the TLR4 pathway in fibroblasts and promotes skin scar formation through collagen I and TGF- $\beta$ in skin lesions. Int J Clin Exp Pathol 12:2121-2129.

33. Monedero V, Buesa J, Rodríguez-Díaz J. 2018. The interactions between host glycobiology, bacterial microbiota, and viruses in the gut. Viruses 10.

34. Samuel G, Reeves P. 2003. Biosynthesis of O-antigens: Genes and pathways involved in nucleotide sugar precursor synthesis and O-antigen assembly. Carbohydr Res 338:2503-2519.

35. Cochet F, Peri F. 2017. The role of carbohydrates in the lipopolysaccharide (LPS)/tolllike receptor 4 (TLR4) Signalling. Int J Mol Sci 18.

36. Lunjani N, Hlela C, O'Mahony L. 2019. Microbiome and skin biology. Curr Opin Allergy Clin Immunol 19:328-333.

37. Grice EA, Kong HH, Conlan S, Deming CB, Davis J, Young AC, Bouffard GG, Blakesley RW, Murray PR, Green ED, Turner ML, Segre JA. 2009. Topographical and temporal diversity of the human skin microbiome. Science (80- ) 324:1190-1192.

38. Brown GC. 2019. The endotoxin hypothesis of neurodegeneration. J Neuroinflammation 16.

39. Matusali G, Colavita F, Bordi L, Lalle E, Ippolito G, Capobianchi MR, Castilletti C. 2019. Tropism of the chikungunya virus. Viruses 11.

40. Garcia M, Wehbe M, Lévêque N, Bodet C. 2017. Skin innate immune response to flaviviral infection. Eur Cytokine Netw 28:41-51.

41. Kim JA, Seong RK, Son SW, Shin OS. 2019. Insights into ZIKV-Mediated Innate Immune Responses in Human Dermal Fibroblasts and Epidermal Keratinocytes. J Invest Dermatol 139:391-399.

42. Regalado NG, Martin G, Antony SJ. 2009. Acinetobacter Iwoffii: Bacteremia associated with acute gastroenteritis. Travel Med Infect Dis 7:316-317. 
43. Ku SC, Hsueh PR, Yang PC, Luh KT. 2000. Clinical and microbiological characteristics of bacteremia caused by Acinetobacter Iwoffii. Eur J Clin Microbiol Infect Dis 19:501505.

44. Seifert H, Dijkshoorn L, Gerner-Smidt P, Pelzer N, Tjernberg I, Vaneechoutte M. 1997. Distribution of Acinetobacter species on human skin: Comparison of phenotypic and genotypic identification methods. J Clin Microbiol 35:2819-2825.

45. Petkovšek Ž, Eleršič K, Gubina M, Žgur-Bertok D, Erjavec MS. 2009. Virulence potential of Escherichia coli isolates from skin and soft tissue infections. J Clin Microbiol 47:1811-1817.

46. Gorrie CL, Mirceta M, Wick RR, Edwards DJ, Thomson NR, Strugnell RA, Pratt NF, Garlick JS, Watson KM, Pilcher D V., McGloughlin SA, Spelman DW, Jenney AWJ, Holt KE. 2017. Gastrointestinal Carriage Is a Major Reservoir of Klebsiella pneumoniae Infection in Intensive Care Patients. Clin Infect Dis 65:208-215.

47. Chang CM, Lee HC, Lee NY, Lee IW, Wu CJ, Chen PL, Lee CC, Ko NY, Ko WC. 2008. Community-acquired Klebsiella pneumoniae complicated skin and soft-tissue infections of extremities: Emphasis on cirrhotic patients and gas formation. Infection $36: 328-334$.

48. Cogen AL, Nizet V, Gallo RL. 2008. Skin microbiota: A source of disease or defence? Br J Dermatol 158:442-455.

49. Spernovasilis N, Psichogiou M, Poulakou G. 2021. Skin manifestations of Pseudomonas aeruginosa infections. Curr Opin Infect Dis 34:72-79.

50. Morand A, Morand JJ. 2017. Pseudomonas aeruginosa in dermatology. Ann Dermatol Venereol 144:666-675.

51. Veraldi S, Nazzaro G. 2016. Skin ulcers caused by Serratia marcescens: three cases and a review of the literature. Eur J Dermatology 26:373-376.

52. Bernard K. 2012. The genus Corynebacterium and other medically relevant coryneform-like bacteria. J Clin Microbiol 50:3152-3158.

53. Rudresh SM, Ravi GS, Alex AM, Mamatha KR, Sunitha L, Thangam Ramya K. 2015. Non 
diphtheritic Corynebacteria: An emerging nosocomial pathogen in skin and soft tissue infection. J Clin Diagnostic Res 9:19-21.

54. Souak D, Boukerb AM, Barreau M, Duclairoir-Poc C, Feuilloley M. 2020. Draft Genome Sequences of Micrococcus luteus MFP06 and MFP07, Isolated from the Skin of Healthy Volunteers. Microbiol Resour Announc 9.

55. Kloos WE, Musselwhite MS. 1975. Distribution and Persistence of Staphylococcus and Micrococcus Species and Other Aerobic Bacteria on Human Skin1. Appl Microbiol 30:381-395.

56. Khayyira AS, Rosdina AE, Irianti MI, Malik A. 2020. Simultaneous profiling and cultivation of the skin microbiome of healthy young adult skin for the development of therapeutic agents. Heliyon 6:e03700.

57. Dréno B, Pécastaings S, Corvec S, Veraldi S, Khammari A, Roques C. 2018. Cutibacterium acnes (Propionibacterium acnes) and acne vulgaris: a brief look at the latest updates. J Eur Acad Dermatology Venereol 32:5-14.

58. Hernandez-Valdes A, Zhou L, de Vries MP, Kuipers OP. 2020. Impact of spatial proximity on territoriality among human skin bacteria. npj Biofilms Microbiomes 6 .

59. Richmond JM, Harris JE. 2014. Immunology and skin in health and disease. Cold Spring Harb Perspect Med 4:1-20.

60. Ryu S, Song PI, Seo CH, Cheong H, Park Y. 2014. Colonization and infection of the skin by S. aureus: Immune system evasion and the response to cationic antimicrobial peptides. Int J Mol Sci 15:8753-8772. 


\section{Figures and tables}

A

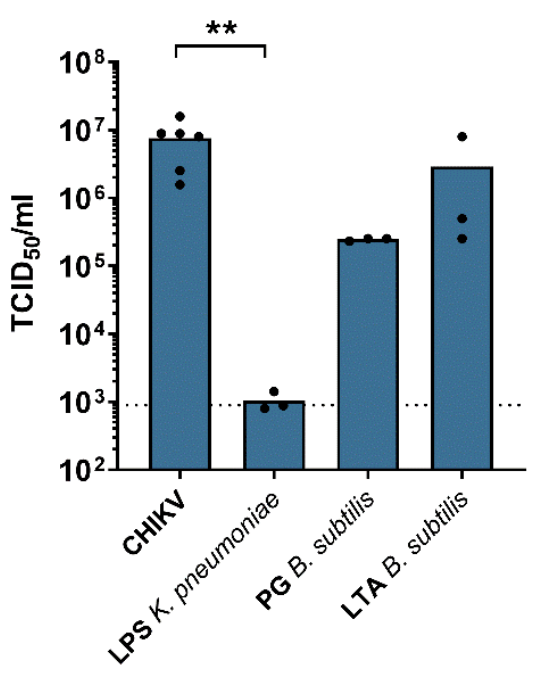

B

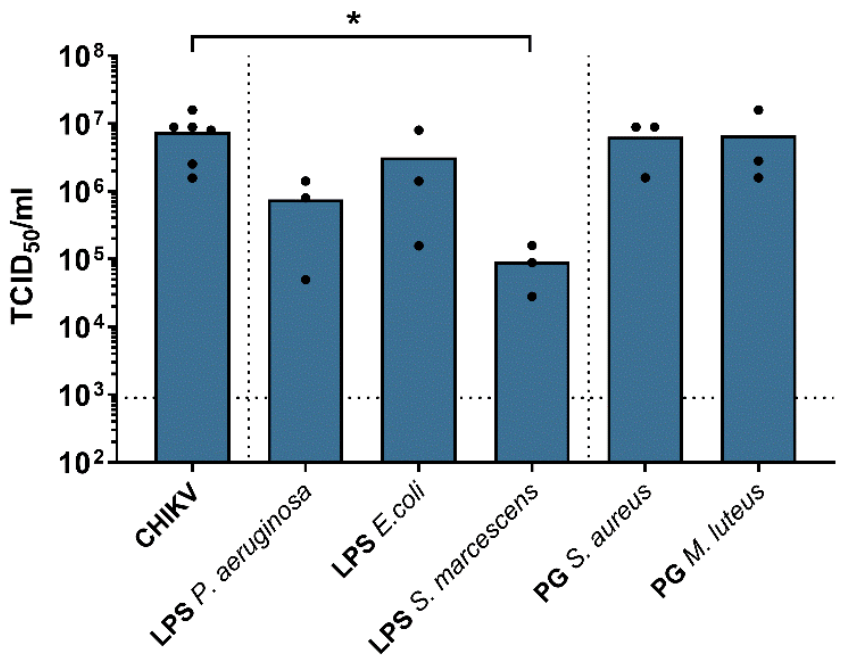

Figure 1. CHIKV infectivity is reduced by different components of the bacterial cell wall.

(A) Infectivity of CHIKV determined by end-point titrations on Vero cells ( $\left.\mathrm{TCID}_{50} / \mathrm{ml}\right)$. CHIKV was incubated with different bacterial cell wall components (LPS of $K$. pneumoniae, PG or LTA of $B$. subtilis) at $37^{\circ} \mathrm{C}$ for $4 \mathrm{~h}$. (B) Infectivity of CHIKV after incubation with an expended panel of LPS (of P. aeruginosa, E. coli and S. marcescens) and PG (of S. aureus and M. luteus) at $37^{\circ} \mathrm{C}$ for $4 \mathrm{~h}$. Individual data points are shown with the height of the bar representing the mean value. Statistical significance was assessed with a Kruskal-Wallis test. Significantly different values are indicated by asterisks: $p<0.05: *, p<0.005:{ }^{* *}$. The dotted line represents the limit of quantification (LOQ). TCID, tissue culture infectious dose; LPS, lipopolysaccharide; PG, peptidoglycan; LTA; lipoteichoic acid. 
A

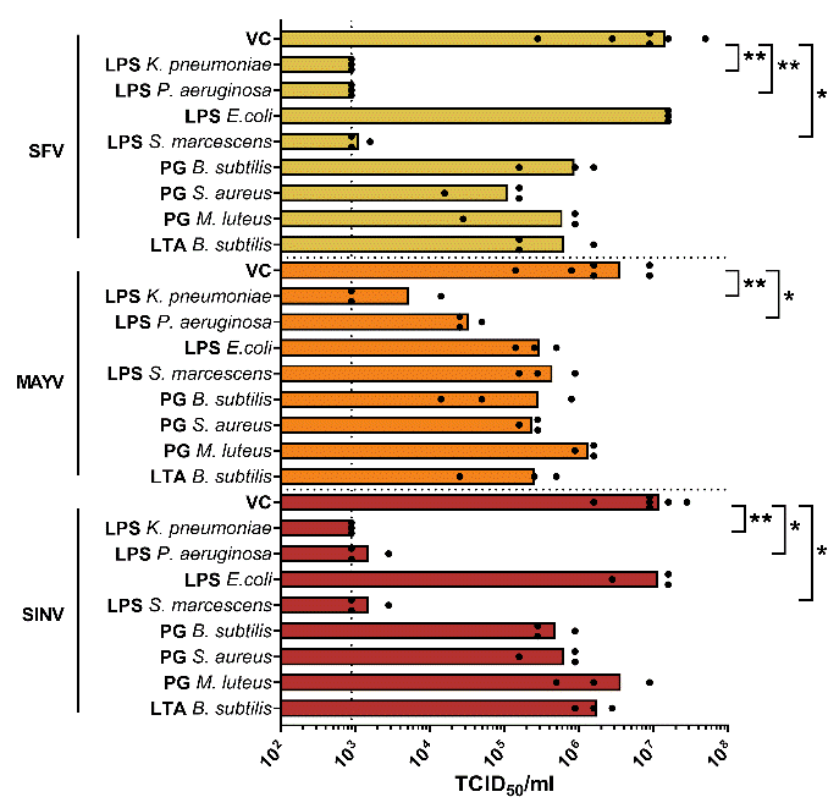

B

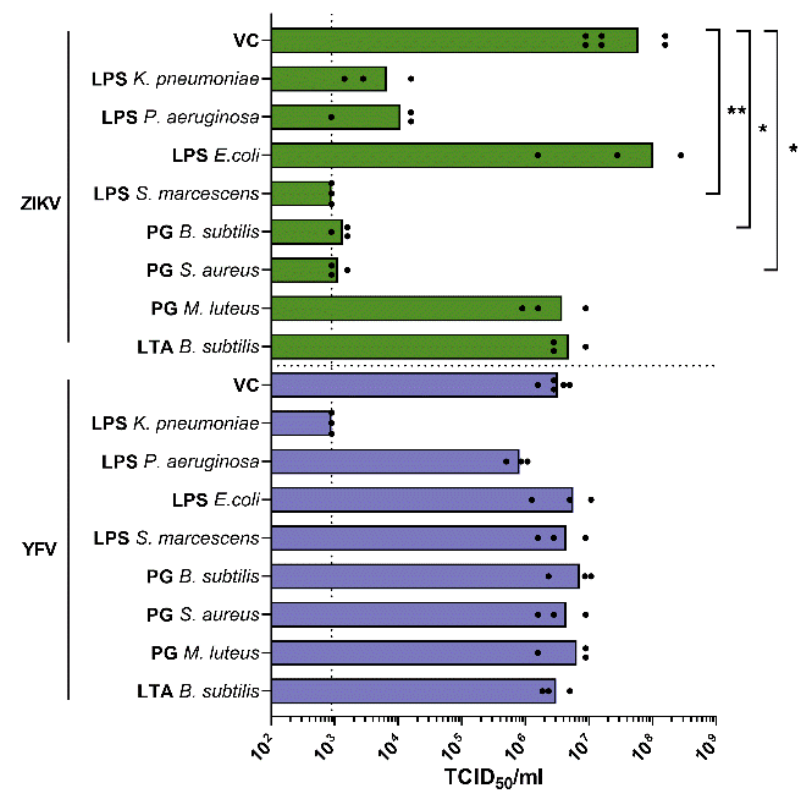

Figure 2. Components of the bacterial cell wall decrease the infectivity of several alphaviruses and flaviviruses.

(A-B) Infectivity of (A) alphaviruses (SFV, MAYV and SINV) and (B) flaviviruses (ZIKV and YFV) quantified by end-point titrations on Vero cells $\left(\mathrm{TCID}_{50} / \mathrm{ml}\right)$. Viruses were incubated with a panel of LPS, PG and LTA of different bacterial species at $37^{\circ} \mathrm{C}$ for $4 \mathrm{~h}$. Individual data points are shown with the height of the bar representing the mean value. Statistical significance was assessed with a Kruskal-Wallis test. Significantly different values are indicated by asterisks: $p$ $<0.05:^{*}, p<0.005: * *$. The dotted line represents the LOQ. TCID, tissue culture infectious dose; LPS, lipopolysaccharide; PG, peptidoglycan; LTA; lipoteichoic acid; VC, virus control. 
A

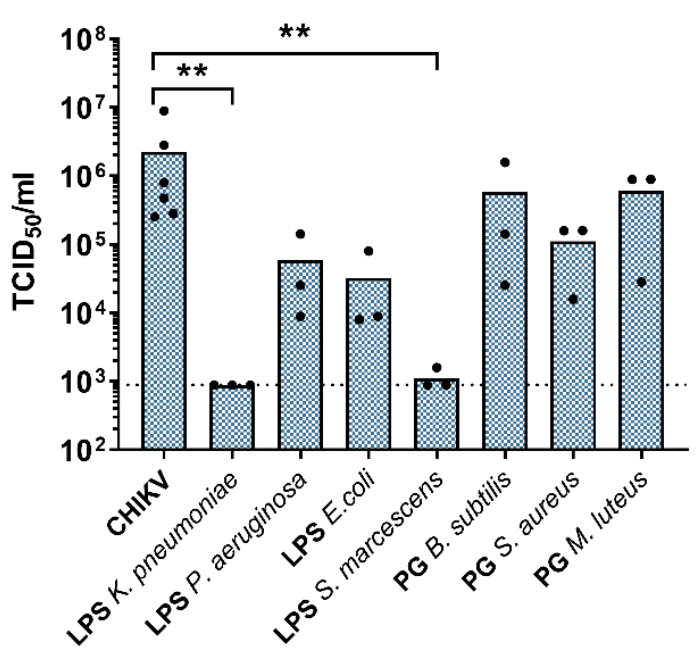

B

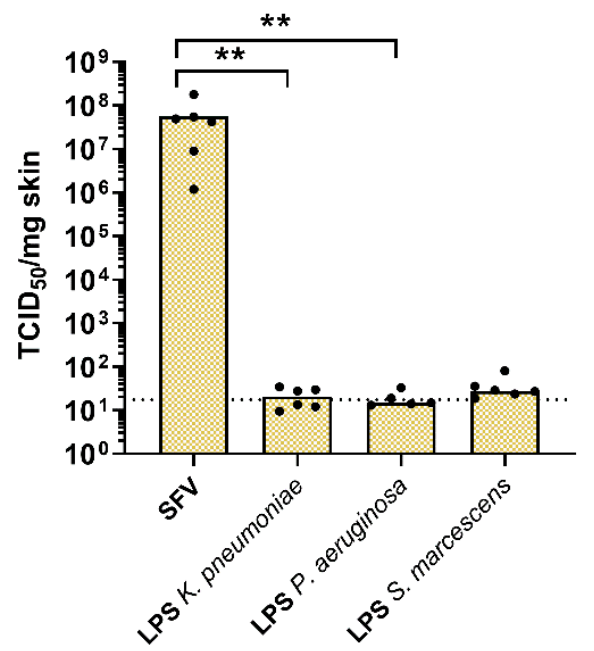

Figure 3. Specific LPS and PG reduce alphavirus infectivity in human skin fibroblasts and ex vivo mouse skin.

(A) Infectivity of CHIKV assessed by end-point titrations on skin fibroblasts (TCID $50 / \mathrm{ml}$ ). CHIKV was incubated with a panel of LPS, PG and LTA at $37^{\circ} \mathrm{C}$ for $4 \mathrm{~h}$. (B) Infectivity of SFV in mouse skin explants. SFV was incubated with LPS of $K$. pneumoniae, $P$. aeruginosa or $S$. marcescens at $37^{\circ} \mathrm{C}$ for $4 \mathrm{~h}$ and was added to skin explants. At day $2 \mathrm{pi}$, infectious virus was quantified by end-point titrations on Vero cells. Individual data points are shown with the height of the bar representing the mean value. Statistical significance was assessed with a Kruskal-Wallis test. Significantly different values are indicated by asterisks: $p<0.005:{ }^{* *}$. The dotted line represents the LOQ. TCID; tissue culture infectious dose; LPS, lipopolysaccharide; PG, peptidoglycan. 
A

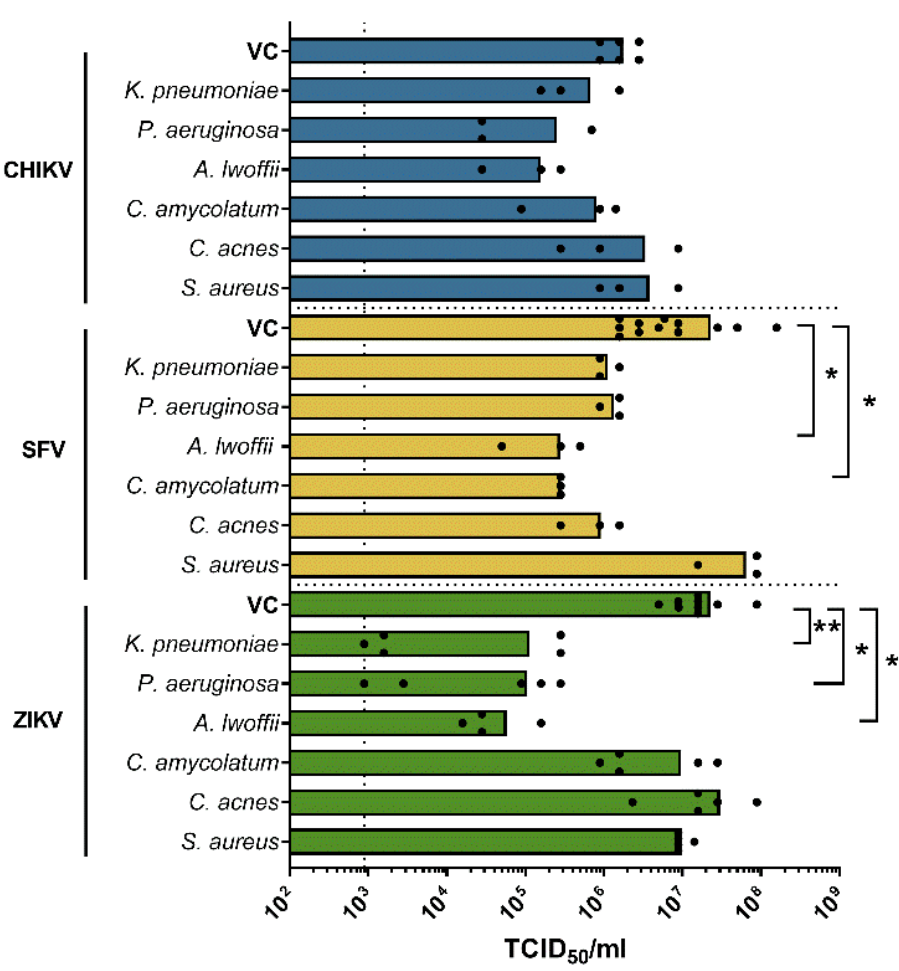

B

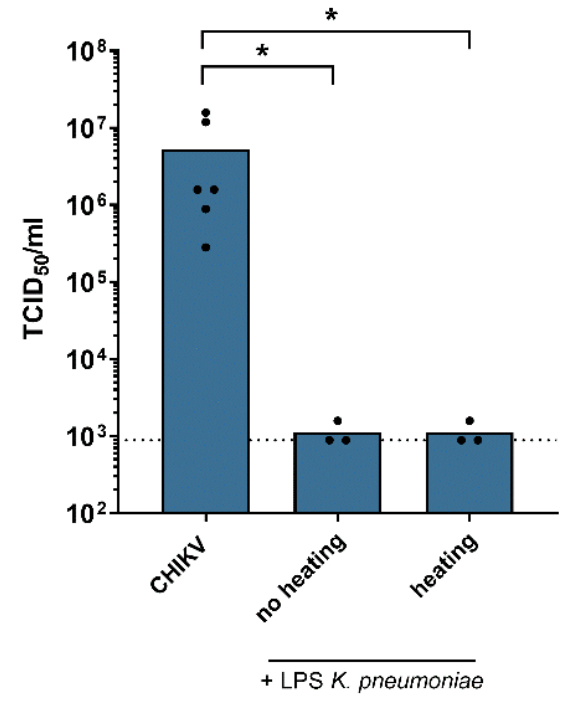

Figure 4. Alphavirus and flavivirus infectivity is reduced by certain heat-inactivated bacteria

(A) CHIKV, SFV and ZIKV infectivity after incubation with Gram-negative (K. pneumoniae, $P$. aeruginosa, A. Iwoffii) or Gram-positive (C. amycolatum, C. acnes, S. aureus) heat-inactivated bacteria at $37^{\circ} \mathrm{C}$ for $4 \mathrm{~h}$. Viral titers were determined by end-point titrations on Vero cells (TCID $50 / \mathrm{ml}$ ). (B) CHIKV infectivity after incubation at $37^{\circ} \mathrm{C}$ for $1 \mathrm{~h}$ with LPS of $K$. pneumoniae or with LPS of $K$. pneumoniae that was pre-heated at $60^{\circ} \mathrm{C}$ for $20 \mathrm{~min}$. Individual data points are shown with the height of the bar representing the mean value. Statistical significance was assessed with a Kruskal-Wallis test. Significantly different values are indicated by asterisks: $p$ $<0.05:{ }^{*}, p<0.005:{ }^{* *}$. The dotted line represents the LOQ. TCID; tissue culture infectious dose; LPS, lipopolysaccharide; VC, virus control. 
A

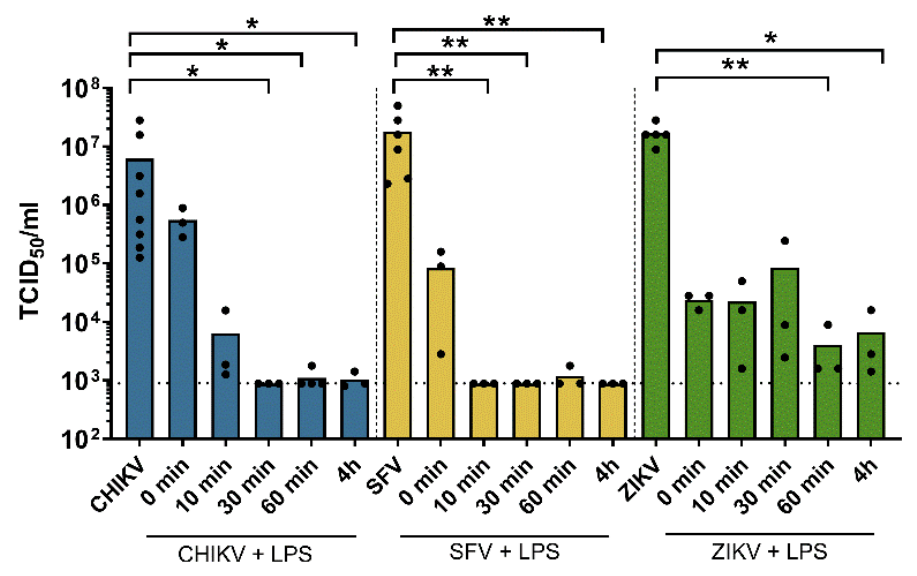

B

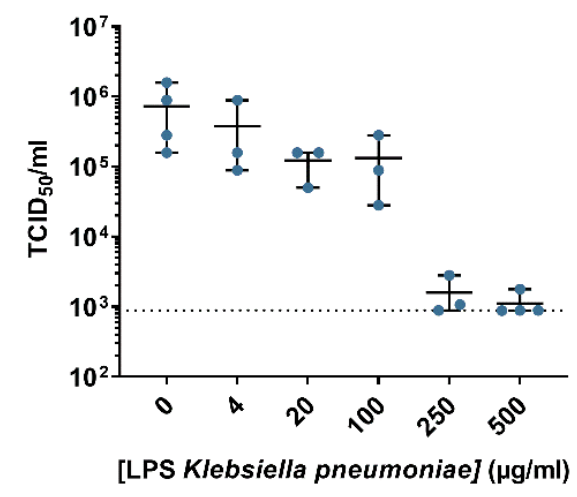

Figure 5. Disruption of virus infectivity is time- and dose-dependent.

(A) Time-dependent effect of LPS of $K$. pneumoniae: infectivity of CHIKV, SFV and ZIKV was determined by end-point titrations on Vero cells $\left(\mathrm{TCID}_{50} / \mathrm{ml}\right)$, after incubation at $37^{\circ} \mathrm{C}$ with LPS of $K$. pneumoniae for different time periods ( $0 \mathrm{~min}, 10 \mathrm{~min}, 30 \mathrm{~min}, 1 \mathrm{~h}, 4 \mathrm{~h}$ ). Individual data points are shown with the height of the bar representing the mean value. Statistical significance was assessed with a Kruskal-Wallis test. Significantly different values are indicated by asterisks: $p<0.05:{ }^{*}, p<0.005:{ }^{*}$. The dotted line represents the LOQ. (B) Dose-dependent effect of LPS of $K$. pneumoniae: CHIKV infectivity after incubation with serial dilutions of LPS of $K$. pneumoniae $(0 \mu \mathrm{g} / \mathrm{ml}, 4 \mu \mathrm{g} / \mathrm{ml}, 20 \mu \mathrm{g} / \mathrm{ml}, 100 \mu \mathrm{g} / \mathrm{ml}, 250 \mu \mathrm{g} / \mathrm{ml}, 500 \mu \mathrm{g} / \mathrm{ml})$ at $37^{\circ} \mathrm{C}$ for $1 \mathrm{~h}$. Individual data points and the mean value are shown. The dotted line represents the LOQ. TCID, tissue culture infectious dose; LPS, lipopolysaccharide 


\section{A}

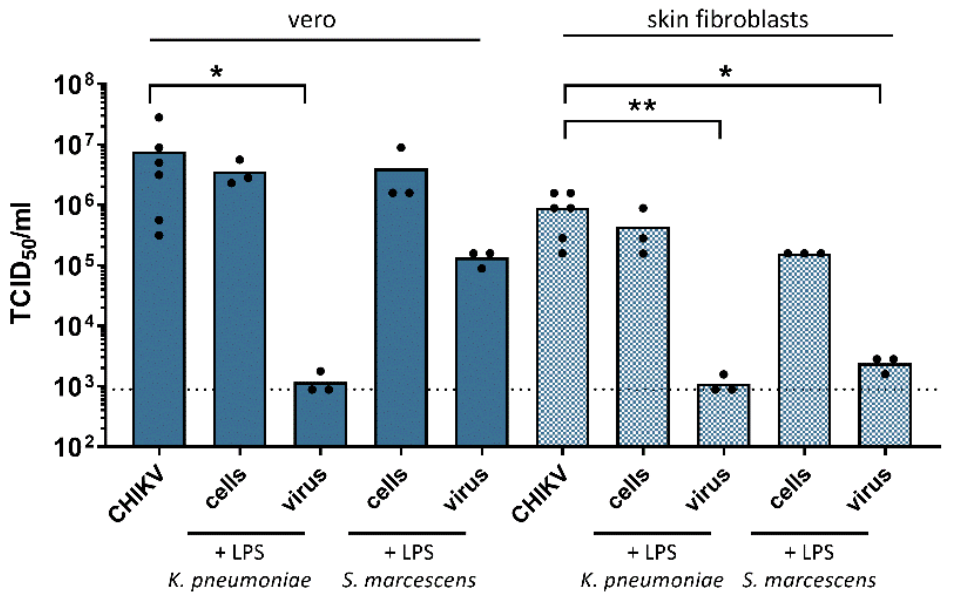

B

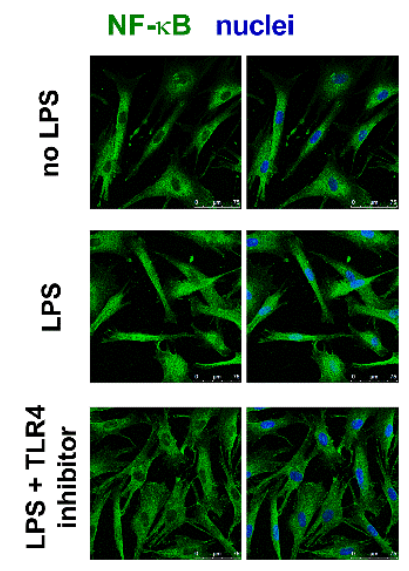

$-75 \mu \mathrm{m}$
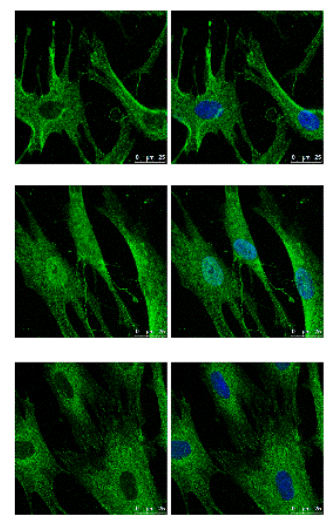

$-25 \mu \mathrm{m}$
C.

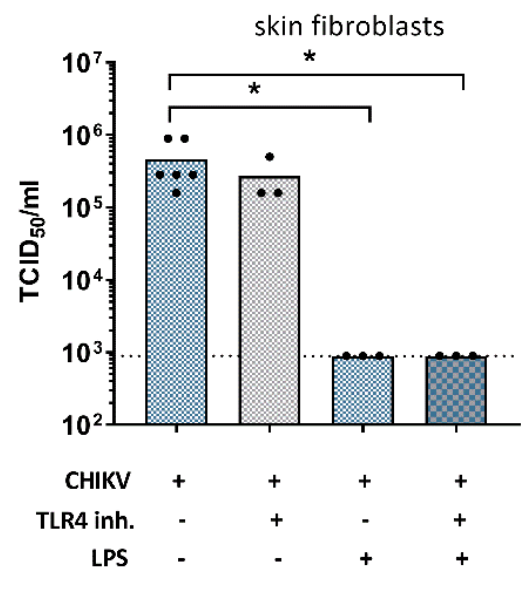

Figure 6. The reduction in virus infectivity is probably not due to a cell-dependent effect.

(A) CHIKV infectivity after pre-incubation of cells (Vero cells or skin fibroblasts) with LPS of $K$. pneumoniae/S. marcescens or after pre-incubation of virus with LPS of $K$. pneumoniae/S. marcescens at $37^{\circ} \mathrm{C}$ for $1 \mathrm{~h}$. Viral loads were determined both on Vero cells and skin fibroblasts by end-point titrations. (B) NF-KB p65 (green) was visualized in skin fibroblast cells cultured for $2 \mathrm{~h}$ in the absence (panel 1) or presence of LPS of $K$. pneumoniae (panel 2) or LPS of $K$. pneumoniae and a TLR4 inhibitor (panel 3) using confocal fluorescence microscopy. Nuclei were stained with Hoechst (blue). (C) CHIKV infectivity determined by end-point titrations on skin fibroblasts $\left(\mathrm{TCID}_{50} / \mathrm{ml}\right.$ ) following incubation for $1 \mathrm{~h}$ with TAK-242, a TLR4 inhibitor and/or LPS of $K$. pneumoniae. Individual data points are shown with the height of the bar representing the mean value. Statistical significance was assessed with a Kruskal-Wallis test. Significantly 
different values are indicated by asterisks: $p<0.05:{ }^{*}, p<0.005:{ }^{* *}$. The dotted line represents the LOQ. TCID, tissue culture infectious dose; LPS, lipopolysaccharide.

A

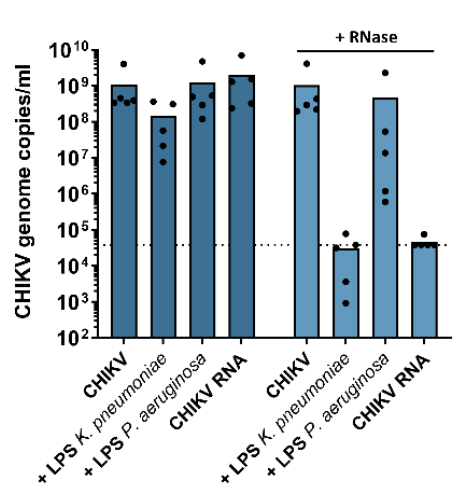

B

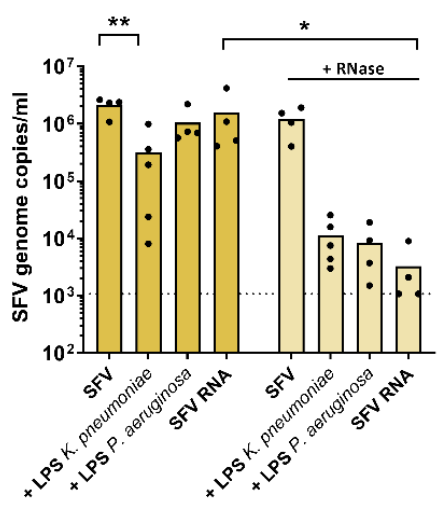

C

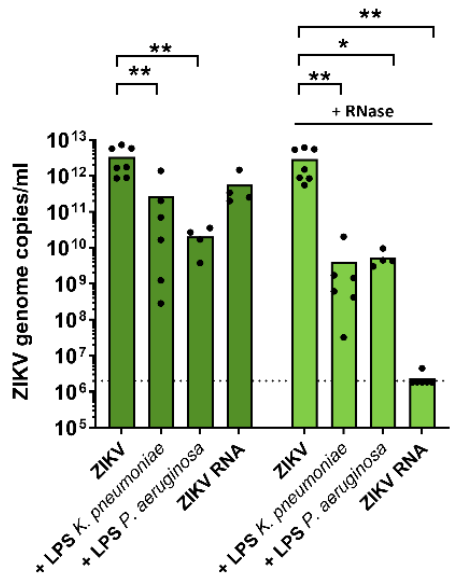

Figure 7. LPS exerts a virucidal effect on alphaviruses and flaviviruses.

(A) CHIKV, (B) SFV or (C) ZIKV genome copies/ml determined by qRT-PCR. After $1 \mathrm{~h}$ incubation at $37^{\circ} \mathrm{C}$ of virus with LPS of $K$. pneumoniae or P. aeruginosa, RNase was added and viral RNA was quantified. Individual data points are shown with the height of the bar representing the mean value. Statistical significance was assessed with a nonparametric Two-way ANOVA with Sidak's correction for multiple comparisons. Significantly different values are indicated by asterisks: $p<0.05:{ }^{*}, p<0.005:^{* *}$. The dotted lines represent the limits of detection (LOD). LPS, lipopolysaccharide. 
A

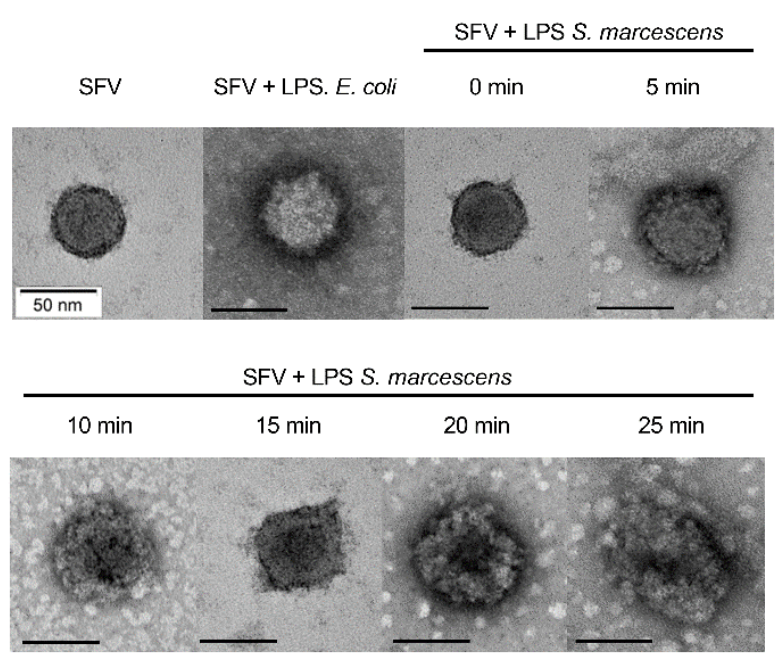

B

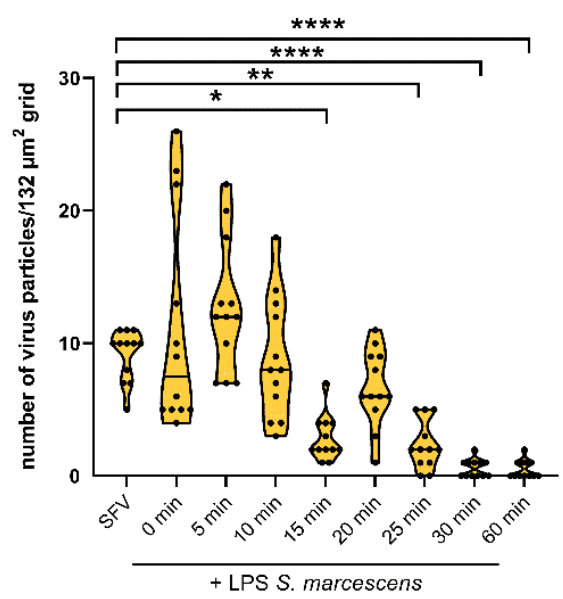

Figure 8. Virucidal effect of LPS of $S$. marcescens on SFV visualized by TEM.

(A) TEM images of SFV or SFV incubated with LPS of E. coli at $37^{\circ} \mathrm{C}$ for $60 \mathrm{~min}$ or SFV incubated with LPS of S. marcescens at $37^{\circ} \mathrm{C}$ for $0,5,10,15,20$ and 25 min. Images were taken at a magnification of $100000 \mathrm{x}$. The black bars represent a scale of $50 \mathrm{~nm}$. LPS, lipopolysaccharide. (B) Number of SFV particles for different incubation times with LPS of S. marcescens. Twelve images were captured for each condition at $4000 \mathrm{x}$ at random positions on the grids (representing $132 \mu \mathrm{m}^{2}$ ) and the number of virions was counted. Data are from 2 independent experiments and are presented in violin plots showing individual data points and medians. Statistical analysis was performed using the Kruskal-Wallis test. Significantly different values are indicated by asterisks: $p<0.05:^{*}, p<0.005:^{* *}, p<0.0001:^{* * * *}$. 
Table 1. Bacterial species used in this study

GRAM STAINING PHYLUM BACTERIAL SPECIES

Negative

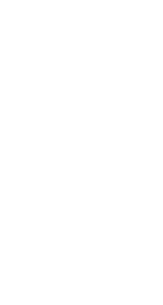

Positive

Actinobacteria

Corynebacterium amycolatum

Micrococcus luteus

Cutibacterium acnes

Firmicutes

Bacillus subtilis

Staphylococcus aureus

\section{COLONIZATION SKIN}

resident of the skin flora (42-44)

rare pathogenic skin colonizer (45)

rare resident of the skin flora (46) + pathogenic skin colonizer (47)

resident of the skin flora (48) + pathogenic skin colonizer $(49,50)$

rare pathogenic skin colonizer (51)

resident of the skin flora + pathogenic skin colonizer $(52,53)$

resident of the skin flora (54-56)

resident of the skin flora + pathogenic skin colonizer (57)

rare resident of the skin flora (58)

resident of the skin flora + pathogenic skin colonizer $(59,60)$ 